\title{
Política Pública e Cultivos Ilícitos na Colômbia
}

\author{
Elizabeth Ruano ${ }^{1}$ \\ Ana Lúcia Valente ${ }^{2}$
}

\begin{abstract}
Resumo: Objetivou-se buscar respostas para diferentes questões associadas ao fenômeno que vincula agricultores familiares com o plantio da papoula. Dentre as quais, saber se a racionalidade imposta mediante a estratégia de desenvolvimento da política de luta contra as drogas ilícitas é compatível com a dinâmica do problema e por que as estratégias dessa política são mantidas mesmo quando seu fracasso é evidente. Tomou-se como método a realização de um estudo de caso sobre o município de Silvia, Departamento de Cauca, sul da Colômbia. Por tratar-se de uma problemática que não se reduz simplesmente à legalidade ou à renda, apresenta-se uma reflexão que retoma os conflitos, a heterogeneidade e as similitudes manifestas nos territórios rurais latino-americanos, no contexto do capitalismo contemporâneo. Constatou-se que o fracasso verificado da política em questão evidencia o descompasso entre a racionalidade da política e a dinâmica dos territórios alvo.
\end{abstract}

Palavras-chave: município de Silvia, Colômbia, pobreza rural, papoula, políticas públicas.

Abstract: This study aimed to find answers to different questions related to the phenomenon which links family farmers to the poppy cultivation. Particularly, it was aimed to find whether the rationality to be imposed by the development strategy of the illicit drugs combat policy is compatible with the dynamics of the problem and why its actions are sustained even when their failure is evident. A case study in the Silvia municipality, Cauca Department, southern region of Colombia, was used as a

1 Doutoranda no Centro de Pesquisa e Pós-graduação Sobre as Américas (CEPPAC). Universidade de Brasília (UnB). Bolsista PEC-PG. E-mail: elizabethruano@gmail.com

2 Dra. em Antropologia Social (USP), com pós-doutorado pela Université Catholique de Louvain (Bélgica). Bolsista de produtividade em pesquisa (CNPq); Associada III da Faculdade de Agronomia e Medicina Veterinária (FAV), da Universidade de Brasília (UnB), atua no Programa de Pós-graduação em Agronegócios (PROPAGA) e no Programa de Pós-graduação em Sociedade, Desenvolvimento e Cooperação Internacional (CEAM). E-mail: ana.valente@pq.cnpq.br 
research strategy. Being this a problem which can not be simply reduced to a matter of legality or income, within this perspective, this research represents a reflection that brings together the conflict, heterogeneity and similarities in the manifestations of the "new countryside" in the territories of Latin America, in the context of contemporary capitalism. Results show that the verified failure of the illicit drugs combat policy in Colombia proves important inconsistencies between the rationality of policy formulators and the dynamic of the territories concerned with the phenomenon.

Key-words: Silvia municipality, Colombia, rural poverty, poppy, public policies.

Classificação JEL: Q18.

\section{Introdução}

Segundo dados oficiais, os agricultores familiares respondem por $20 \%$ da produção de papoula na Colômbia (COLÔMBIA, 1994). O cultivo de papoula expande-se em territórios vulneráveis ambiental e socioeconomicamente. No caso aqui apresentado, é evidente que prevalece o clássico problema agrário de acesso à terra e os efeitos dele decorrentes tomaram diferentes matizes que constituem o motor da dinâmica social territorial. Silvia é um município pequeno, eminentemente rural. Possui 42.198 habitantes, uma extensão territorial de $813 \mathrm{~km}^{2}$ e densidade demográfica de 52 habitantes $/ \mathrm{km}^{2}$. Localiza-se no Departamento ${ }^{3}$ de Cauca, no sul do país. Tem sido catalogado como o terceiro município colombiano em relação à porcentagem de povos indígenas que abriga.

Neste trabalho, a partir da visão dos atores locais ante ao fenômeno da papoula, são problematizadas as tensões e as contradições diante da política pública orientada à mitigação da problemática. $\mathrm{O}$ município de Silvia permite observar os efeitos perversos da filosofia integracionista em matéria de povos indígenas na Colômbia. Isto é, existem territórios indígenas, legalmente constituídos, a maioria no setor rural, mas foram reduzidos e localizados em terras sem aptidão para a exploração agrícola. Mesmo assim, as políticas públicas para o rural, apesar da reforma constitucional na qual o país se declarou pluriétnico e multicultural, abordam o rural como uma totalidade homogênea. No caso da política de luta contra as drogas, fala-se em pequenos produtores inseridos no plantio ilícito. Não é explicitado que essa categoria abrange uma multiplicidade de atores que exigem abordagens diferenciadas. Neste ensaio, usa-se a categoria agricultura familiar construída por autores brasileiros, com o intuito de trazer ao debate a existência de um grupo social do rural colombiano, incluindo indígenas e não indígenas, no qual o caráter familiar da sua produção apresenta-se como um traço fundamental.

3 Na divisão política da Colômbia, há Departamentos e Municípios. O Departamento constitui uma unidade administrativa similar à do Estado federal no Brasil. 
Além da introdução, na estrutura do artigo, apresenta-se o seguinte conteúdo: a descrição metodológica da pesquisa; uma breve contextualização histórica sobre o fenômeno da concentração da terra; a sistematização das percepções e reações dos atores locais diante da expansão da papoula; uma descrição da política pública de luta contra os cultivos ilícitos e, finalmente, a conclusão e a bibliografia.

\section{Metodologia}

O método usado foi o estudo de caso. O caso reúne várias características interessantes. De um lado, a existência de um movimento social indígena que efetivou uma alternativa diferente da fumigação, como mecanismo para a erradicação dos cultivos da papoula. De outro lado, o fato de que, na época, havia famílias plantando papoula.

Outros critérios que orientaram a escolha deste município foram: i) relativa facilidade e segurança para o acesso à região; ii) conhecimento prévio da região e dos atores locais e iii) o desenvolvimento atual de projetos no âmbito da política de controle aos cultivos ilícitos que oferece uma plataforma institucional e facilita a interlocução com os atores e a coleta de dados.

A pesquisa de campo foi realizada durante quatro meses, porém, destaca-se a proximidade pré-existente com esses atores desde o ano 2000. A ferramenta de pesquisa privilegiada foi a entrevista semiestruturada. A amostra ${ }^{4}$ da pesquisa se formou com 21 (vinte e um) informantes ${ }^{5}$ : agricultores familiares sem envolvimento direto com o plantio da papoula; agricultores familiares com envolvimento direto nesse plantio - casos de passagem pela cadeia; alguns ainda hoje plantam papoula; outros atualmente recebem subsídios dos projetos de substituição -; e lideranças locais. Destaca-se a experiência de alguns informantes em cargos de eleição popular: prefeitura municipal, governo departamental, governadores indígenas ${ }^{6}$, no Senado, e no processo da "Assembléia Constituinte ${ }^{7 "}$.

4 As indicações de dois funcionários da prefeitura sobre a situação atual municipal foram determinantes, não somente para identificar os informantes adequados, mas, também, para tomar as providências e prevenções necessárias em relação à segurança, principalmente para com os próprios pesquisados.

5 Todos os informantes são do sexo masculino. Apesar disso, os depoimentos revelam a importância da mulher na tomada de decisões. Embora essa participação seja discreta em espaços públicos, as decisões em relação à família são tomadas segundo a tradição nas conversas diante do fogão, no espaço doméstico.

6 Reconhecidos constitucionalmente como órgãos de governo, com funções administrativas, legislativas e jurisdicionais sob seus territórios.

7 Iniciativa desenvolvida entre abril e junho de 1991 para reformar a Constituição Política de 1886. Como resultado surgiu a Constituição Política de 1991, vigente atualmente. 
Foram realizados até três encontros com cada informante. Inicialmente, foi apresentado o interesse do pesquisador, e procurou-se o consentimento dos informantes para participar. Em alguns casos, a permissão para gravar entrevistas não foi outorgada. Em nenhum dos casos foi autorizada a tiragem de fotografias ${ }^{8}$. Assumiu-se o compromisso de tratar as informações dadas com sigilo - reserva e proteção da identidade ${ }^{9}$. Nos três roteiros de perguntas elaborados, indagou-se sobre os seguintes temas centrais: papoula, agricultura familiar, desenvolvimento e políticas públicas.

\section{A concentração da terra na Colômbia: breve resenha histórica}

A região geográfica onde atualmente se localiza Silvia integrava a "Gobernación de Popayán" dentro do vice-reinado da "Nueva Granada" durante o império espanhol ${ }^{10}$. A irrupção espanhola no século XVI determinou uma ruptura no processo histórico das sociedades indígenas. Na maioria dos casos, destruiu, ou pelo menos alterou profundamente, processos econômicos, políticos e sociais próprios. Uma nova organização econômica e social se definiu, sustentada em instituições como a "mita" ${ }^{11 "}$ e a "encomienda" ${ }^{12 "}$ e,

8 Segundo Vargas (1999), no início do "boom" do cultivo da papoula, os agricultores familiares permitiam o acesso de fotógrafos em suas propriedades. Com as evidências capturadas, os agricultores eram, depois, denunciados como papouleiros, sinônimo de serem delinquentes. Isso explica porque os agricultores familiares têm prevenção para fornecer informações e principalmente para permitir a captura de fotografias.

9 Apesar de contar, em alguns casos, com a autorização para revelar a identidade dos informantes, decidiu-se proteger a identidade de todos eles. São usadas as seguintes siglas para referirmos os informantes: ALn - - Autoridade Local -; AFPno - Agricultor Familiar com envolvimento no cultivo da papoula-; AFno - Agricultor Familiar sem envolvimento direto com a papoula-.

10 Esse vice-reinado compreendeu os territórios atuais da Colômbia, Equador, Panamá, Venezuela, as regiões do norte do Peru e Brasil e o leste da Guiana. Essa estrutura territorial permaneceu entre 1717 e 1819, e a independência definitiva da Coroa Espanhola foi alcançada em 1819.

11 Esta instituição teve origem na sociedade indígena (FALS BORDA, 1975). Os espanhóis exploravam a mão-de-obra indígena como tributo. A queda demográfica, devido às extenuantes jornadas nesse trabalho, trouxe a destruição da vida familiar e social indígena.

12 Instituição originaria do sistema feudal espanhol. Dignidade vitalícia outorgada aos militares. Na América, consistia na administração de comunidades indígenas para a produção de tributos em espécie - alimentos, tecidos, ouro. Sob este mecanismo, os nativos eram obrigados a prestar serviços - coletar lenha e forragens para animais, reparação de casas. Os exagerados tributos durante longas jornadas de trabalho provocaram o abandono dos cultivos próprios, gerando a dependência dos nativos para garantir o sustento familiar. 
posteriormente, a "fazenda" e o "resguardo". A "fazenda" tomou força como a instituição político-econômica dominante.

Os "resguardos ${ }^{13 "}$ foram criados como expressão deste movimento de redução da terra dos indígenas, por ordem da Coroa espanhola. Conforme Fajardo (1986, p. 436), “os resguardos indígenas não são concentrações naturais de indígenas, são núcleos formados artificialmente como conseqüência do despojo formal ou forçoso da terra ao que eram submetidos". A terra outorgada era a menos apta para atividades agrícolas e distante das cidades.

A fragmentação dos territórios das comunidades indígenas ficou mais aguda na década de 1810, período após a independência da Coroa Espanhola. A nascente república foi rodeada por fortes contradições: uns advogavam por um esquema mais liberal e outros defendiam o velho esquema instaurado durante a colônia. Finalmente se estabeleceram regimes e políticas similares às praticadas pelos espanhóis, prevalecendo "a tendência na redução das terras dos indígenas, a ampliação das fazendas, a liberação do comércio e o regime de impostos" (KALMANOVITZ, 1994, p. 94). Reduzida sua terra, os índios incrementaram o grupo de peões, posseiros, "terrajeros ${ }^{14 "}$ e arrendatários das fazendas (JARAMILLO, 2002).

Essa dinâmica constitui a base para a formação de um heterogêneo rural, caracterizado por uma tensa inserção econômica e social de seus habitantes. Esses atores se constituíram no gérmen do movimento social de luta pela terra com o qual os indígenas e as populações pobres reclamaram apoio estatal para fortalecer suas instituições, defender sua história e seus costumes. Este processo se iniciou no começo da década de 1970, e se constitui na expressão da crise de territorialidade provocada pela "fazenda".

Diante do confronto entre latifundiários e povos indígenas no Departamento de Cauca, o governo tentou ignorar que tal confrontação realmente significava uma crise territorial. Adotando um tratamento de acordo com uma interpretação enviesada de tal situação, na medida em que se desconsiderou a racionalidade dos povos indígenas, diferente da racionalidade econômica. Nesse conflito, predominou a concepção da "terra como mercadoria, mero instrumento de troca e produção, que pode ser comprada e vendida em qualquer lugar". À margem

13 Criados mediante cédula real da coroa espanhola. Vigência ratificada pela Lei número 89 de 1890, mediante a qual se reconhece o direito de propriedade das comunidades indígenas sobre as terras que ocupam, sendo elas inalienáveis. As reservas indígenas foram estabelecidas posteriormente, nesse caso, a propriedade da terra é do Estado, e ele outorga o usufruto em forma coletiva às comunidades indígenas (MACHADO, 1986).

14 A "terrajeria" teve início em 1750. Sistema no qual um fazendeiro faz uso do trabalho indígena e, em troca, o indígena usa um pedaço pequeno de terra dentro da fazenda. A diferença existente entre ela e o arrendamento está em que as terras objeto de transação eram inicialmente de propriedade dos indígenas. $\mathrm{O}$ trabalhador vinculado neste esquema de exploração denomina-se "terrajero" (MUELAS e URDANETA, 2005). 
ficou o ponto de vista, no qual "a terra como morada ancestral, referência de um modo de viver e de uma consciência do mundo que, suprimida, desencadeará o desaparecimento social e cultural de seus protagonistas" (MARTINS, 2008).

Esta circunstância constituiu-se no fator detonante para o surgimento do Movimento Social Indígena de Cauca. O avanço do capitalismo durante o século XX tinha contribuído para que a concentração da propriedade da terra originada na sociedade colonial que alcança cifras lamentáveis: $60 \%$ da área rural é propriedade de 0,4 proprietário. Em contraste, 1,7\% da área rural é propriedade de $57,3 \%$ dos agricultores familiares que exploram unidades produtivas inferiores a três hectares (COLÔMBIA, 2002).

Além do fracasso evidente da reforma agrária, nas décadas recentes, fala-se em outro fenômeno que influenciou a concentração da terra: a "contra-reforma" agrária, a qual estaria sendo dinamizada pela força armada ilegal e pelo capital do narcotráfico ${ }^{15}$. Esta nova problemática, entre outras consequências, estaria colocando em risco a democracia. Diante dessa ameaça, a "extinción de dominio" para as propriedades dos narcotraficantes foi colocada como a "nova via" para a reforma agrária. Os avanços nesse sentido são mínimos. A administração Uribe tinha como meta para o período 2002-2005, entregar cento e cinqüenta mil hectares. Mas, durante 2003-2004 somente foram entregues aproximadamente cinco mil hectares, quantia inferior a $5 \%$ da meta estabelecida.

\section{A expansão da papoula segundo os atores locais}

Ao indagar sobre as lembranças que os informantes têm sobre a chegada do cultivo da papoula ao município, coincidem em afirmar que na década de 1970 se começou a falar na existência dessa lavoura. Não obstante, afirmam que somente na década 1980 esse cultivo se ampliou e que, na década de 1990, atingiu-se o apogeu do cultivo. Todas as informações apontam que "forasteiros" trouxeram as primeiras sementes da papoula comercial. Contudo, há quem afirme que não é invenção que nesta localidade sempre existiu um tipo de papoula silvestre, mas que não era explorada para fins ilícitos.

Alguns fatores contribuíram para que o município de Silvia se convertesse em alvo desse plantio. O primeiro fator está associado à aptidão do solo e ao clima para essa lavoura. O segundo estaria constituído pelo isolamento territorial, fator decisivo na tentativa de evadir o controle governamental. $\mathrm{O}$ terceiro, a proximidade geográfica com os centros de operação dos cartéis da máfia: principalmente com o Departamento do Valle, sede dos cartéis da máfia de Cali e Valle (VARGAS, 1995).

15 Segundo Rocha (2000), os narcotraficantes teriam a posse de 4,4 milhões de hectares de terra. De outro lado, o Incora afirma que as terras de propriedade dos narcotraficantes alcançam $50 \%$ das melhores terras agricultáveis. 
Conforme discutido, fatos ligados à configuração histórica deste território deixaram-lhe um legado que tem contribuído para a deterioração econômica e social. Os informantes denunciam o problema de concentração da propriedade da terra como um conflito histórico. $\mathrm{O}$ acesso à terra no município de Silvia é um fator problemático ressaltado em todos os depoimentos desta pesquisa. Porém, outros problemas associados à produção agrícola são identificados nessas falas.

Não é errado afirmar que as limitações associadas ao acesso à terra têm parcela de responsabilidade na expansão da papoula neste município. Porém, há uma mistura de fatores problemáticos decorrentes da pobreza rural e da prevalência de um enfoque de desenvolvimento que iguala a vida rural com produção agrícola. Uma das principais lacunas dessa abordagem é que ela subestima a heterogeneidade das sociedades rurais e o caráter multidimensional da pobreza que estas sofrem.

Esta pesquisa evidenciou que a expansão da papoula foi ampla e dinâmica, porém, um segmento importante de agricultores familiares conseguiu manterse à margem desse fenômeno. Segundo os depoimentos, a condição de ser um ator reconhecido dentro da estrutura social do território obrigava a manter uma atitude de recusa desse plantio. Ser parte ativa da estrutura social implica o desfrute do reconhecimento social e, principalmente, a oportunidade de participar na tomada de decisões e beneficiar-se dos investimentos públicos que atingem a reduzidos segmentos da população. $O$ vínculo estreito com o trabalho comunitário dentro dos territórios indígenas é ressaltado nos depoimentos dos agricultores familiares não vinculados à exploração da papoula

Outra característica comum entre os agricultores familiares que não se vincularam com o cultivo da papoula está relacionada com o grau de instrução: este é superior, se comparado ao dos produtores envolvidos no plantio da papoula, os quais manifestaram não ter concluído o ensino básico. Não obstante, todos os casos pesquisados, o grau de instrução dos informantes não supera o ensino fundamental. A educação pública na Colômbia não é gratuita, mas constitucionalmente se afirma o contrário. No município de Silvia, a oferta educativa fornecida chega até o ensino médio. Destacam-se alguns avanços no tocante à educação indígena. Este processo é sustentado na idéia de fortalecimento da identidade.

A nossa educação própria se inspira nas tradições culturais. É um processo que inicia no fogão, no interior da família. Reconhecemos a importância que a família tem na educação do indivíduo. Embora o indígena contemporâneo tenha que entender que precisa conhecer o mundo onde ele está inserido. Esse mundo que não entendemos e nos ataca constantemente (AL1. Entrevista realizada em 4/12/2007).

A quarta característica presente nos agricultores familiares que não plantam papoula é relacionada com a "combinação de múltiplas inserções ocupacionais 
das pessoas que pertencem a uma mesma família" (SCHNEIDER, 2005, p. 26). A combinação de duas ou mais atividades, sendo necessariamente uma delas a agricultura, é um recurso que lhes permite garantir a reprodução social dessas famílias.

De outro lado, os agricultores familiares envolvidos no plantio da papoula apresentam como traço comum o fato de tentar subsistir mediante a exploração de uma extensão de terra inferior a um hectare. Esses testemunhos indicam que sua inserção no plantio da papoula aconteceu da mesma forma como quem experimenta um cultivo novo, visando mudar o desequilíbrio entre capacidade produtiva e consumo familiar. Cultivar papoula não significa somente a ilusão de incrementar a renda familiar. Essa cultura produtiva apresenta diferenciais que constituem a oportunidade de superar problemas intrínsecos ao desenvolvimento agrícola do município. Em primeiro lugar, a lavoura da papoula não exige disponibilidade de terra: "como mínimo devem ser plantadas cinco mil plantas, as quais cabem em um quarto de hectare" (AFP6. Entrevista realizada em 13/12/2007). De outro lado, oferece a possibilidade de associar-se com outras culturas, fator que é também é aproveitado para dissimular o plantio ilícito diante do controle das autoridades.

Esta é uma região de minifúndio. Então as pessoas não têm mais de um quarto de hectare de terra para cultivar. Nesse sentido, a papoula se misturou com outros cultivos, ou seja, se plantava papoula, cebola, milho, tudo junto. Os cultivos nossos sempre têm sido associados. Em um pedaço de terra, há de tudo cultivo. É uma mistura que constitui o sustento da gente (AL2. Entrevista realizada 10/12/2007).

Em segundo lugar, todos os testemunhos destacam a facilidade de crédito que surgiu para comprar insumos para a produção da papoula. Como colocado por Perafan (1999), os narcotraficantes aproveitaram o "vazio" existente no sistema de crédito e estabeleceram como estratégia, uma linha de crédito que incentivava a lavoura da papoula: "a gente somente tinha que dizer que desejava plantar papoula, tudo era fornecido. Nem parecido com aquela agonia quando a gente quer plantar outra cultura" (AL2. Entrevista realizada 10/12/2007).

A agonia referida no depoimento acima se refere aos constrangimentos sofridos pelos agricultores familiares que, despossuídos de capital, solicitam apoio do sistema de crédito governamental. Apesar de existir linhas de crédito para esse segmento, as dificuldades de acesso ao sistema evidenciam o desconhecimento das particularidades da agricultura familiar. Em muitas ocasiões, esses agricultores não possuem as garantias exigidas pelas entidades bancárias como, por exemplo, o título de propriedade da terra, inexistente nas comunidades indígenas. De outro lado, ao administrar os recursos de crédito, o agricultor familiar se depara com uma contradição que nem sempre consegue superar com sucesso. Acostumado a governar a renda familiar como 
um conjunto indivisível, os recursos do crédito serão usados não somente no incremento da produção, mas, também, nas necessidades da família. Assim, assumir uma obrigação creditícia implica para o agricultor familiar mudanças na lógica de funcionamento na sua unidade produtiva. Isto é, sua preocupação maior teria que ser o pagamento oportuno da dívida mediante o incremento da produção.

$\mathrm{Na}$ maioria dos casos, o crédito adquirido não consegue aumentar os excedentes comercializáveis, e o agricultor converte-se em devedor sem capacidade de pagamento da sua dívida. No caso de Silvia, um número elevado de agricultores encontrava-se nessa situação. A decadência de algumas culturas produtivas de subsistência contribuiu com essa conjuntura. O cultivo da cebola decresceu, dados os problemas biológicos e fitossanitários decorrentes da pressão exercida sobre o solo. A produção dos cultivos da batata, milho e trigo diminuiu pela alta demanda de adubos e pela insuficiência de recursos para comprá-los.

Em terceiro lugar, a papoula é uma cultura produtiva de ciclo curto, fato que constitui outra característica diferenciadora. O ciclo produtivo da papoula dura quatro meses. Nos casos da batata e da cebola são seis meses, e oito meses no caso do milho tradicional. Aliás, o látex obtido da papoula não é perecível, assim pode ser estocado na espera de maiores preços para a comercialização.

Finalmente, ninguém a contradiz, a diferença que constitui o incontestável valor de mercado do látex da papoula diante das culturas produtivas tradicionais (THOUMI et al., 1997): "o custo de um quilograma chegou a 10 milhões de pesos [aproximadamente US\$ 5.000]: era muito rentável" (AL2. Entrevista realizada 10/12/2007).

O destaque de motivações diferentes ao valor de mercado da papoula, e o consequente impacto na renda das famílias produtoras, pretende mostrar que na equação que estimulou esse plantio não somente se consideraram cálculos economicistas. Nessa decisão, a ação econômica é orientada pelo acúmulo de experiências passadas na tentativa de garantir um melhor amanhã. Ou seja, as facilidades oferecidas pelo cultivo de papoula foram enxergadas como uma alternativa real e efetiva para os problemas que ameaçavam a subsistência dessas famílias.

$\mathrm{O}$ aumento dos agricultores vinculados ao plantio da papoula crescia ao constatarem as melhoras alcançadas pelos vizinhos e amigos pioneiros na atividade. Ninguém parecia importar-se com os efeitos nocivos da papoula. Pouco tempo depois, era notória a alteração na dinâmica socioeconômica municipal.

Há um sentimento de desencanto diante deste cultivo. A gente pode olhar as conseqüências ruins. E como dizem as propagandas da rádio, com os cultivos de uso ilícito a gente apronta a cadeia, o cemitério ou os hospitais, nada mais. A comunidade não tem melhorado. Muito pelo contrário, há perdas na parte econômica e social (AFP3. Entrevista realizada em 31/01/2008). 
As consequências não dimensionadas pelos atores locais no auge do plantio transformaram a sua cotidianidade. As denúncias dos informantes desta pesquisa incluem aspectos que vão desde a insegurança alimentar, por terem deixado de plantar as culturas de subsistência, passando pelas deformações nos filhos dos agricultores familiares vinculados ao processamento do látex de papoula, até o incremento do consumo local da morfina. Na lista de consequências associadas ao fenômeno da papoula, também se incluem a desintegração dos núcleos familiares, alterações no padrão de consumo e o incremento do alcoolismo, principalmente entre os adolescentes. O plantio da papoula trouxe novos conflitos ao território, mas também permitiu incrementos na renda, principalmente durante a década de 1990. É paradoxal que esses agricultores afirmem que um fato positivo da bonança gerada pelo plantio da papoula foi o pagamento dos créditos em mora com o sistema financeiro (PERAFAN, 1999).

\section{Reações locais à expansão da papoula}

Diversas contradições floresceram no território com a chegada do cultivo da papoula. Múltiplos esforços desenvolveram as lideranças indígenas locais para impedir que esse cultivo ilícito se expandisse no município de Silvia. As declarações registradas dão conta das iniciativas que surgem localmente, inclusive antes de serem instados pelo governo nacional. Porém, essas manifestações foram dizimadas pela imposição do enfoque e das estratégias da política de controle às drogas ilícitas.

A expansão do cultivo ilícito da papoula apareceu nas reservas indígenas como uma problemática nova, para a qual a autoridade indígena não estava preparada. Não obstante, as autoridades indígenas reagiram. A ausência governamental diante desse fenômeno foi determinante para que as lideranças indígenas assumissem o comando dos mecanismos de mitigação da expansão papouleira.

Entre as autoridades indígenas, havia consenso de que a expansão da papoula constituía uma ameaça para os processos sociais em andamento. É importante advertir que há diferenças entre os povos indígenas que a presente pesquisa abordou: Guambianos, Kisweños e Pitagueños. As diferenças aqui apresentadas se referem aos "seus processos históricos, suas características socioculturais, sistemas produtivos e econômicos, condições ambientais e recursos naturais disponíveis" (LONDOÑO, 2005, p. 2). Mesmo assim, cada povo indígena tem alcançado diferentes níveis de maturidade e mediação política. No caso dos guambianos, representantes dessa comunidade desempenharam cargos de eleição popular no âmbito nacional, o que, indubitavelmente, gerou novas capacidades de mediação política. Assim, não há similitude nos mecanismos de interação entre eles e com atores externos. Principalmente, não se pode equiparar o grau de interlocução com as instituições governamentais. 
As diferenças acima destacadas influenciaram as estratégias de controle da expansão do cultivo da papoula. Os relatos documentados trazem explicações sobre porque esse cultivo não prosperou em alguns territórios indígenas, apesar de possuírem as condições favoráveis para esse plantio. Por outro lado, também é contextualizada a situação vivida em alguns locais onde não surgiram mecanismos próprios de controle da expansão dessa lavoura ilícita.

\section{As reações na Reserva Indígena de Guambia}

Nesta reserva, a autoridade indígena iniciou um tímido processo de erradicação voluntária da papoula na década de 1980. Porém, diante dos confrontos entre os que plantavam papoula e as lideranças que promoviam a erradicação, esse mecanismo foi abandonado. Simultaneamente à expansão do plantio da papoula se levantava o movimento social de luta pela "recuperação das terras indígenas". Nessa perspectiva, os índios apresentavam-se como donos legítimos que "recuperam" suas terras, das quais foram expulsos injustamente. Desvirtuam assim as denúncias sobre "invasão" de terras (LONDOÑO, 2005).

Conforme os depoimentos, o conflito interno gerado pela erradicação da papoula era um preço que a autoridade Guambiana não estava disposta a pagar naquele momento. A liderança desta comunidade estava focada em gerar consenso diante do processo de luta pela terra. Por isso, procurava-se a todo custo manter a unificação em torno desse objetivo comum. Qualquer motivo gerador de oposição ou controvérsia era evitado.

Posteriormente, na década de 1990, o Movimento Indígena Guambiano alcançou importantes avanços para a ampliação das terras do seu território. Há informações indicando que, em três anos desse movimento, os indígenas conseguiram $80 \%$ mais de terras que as regularizadas em 10 anos do processo de Reforma Agrária (LONDOÑO, 2005). Porém, esse resultado contrastava com a expansão do cultivo da papoula em quase toda a reserva.

Nesse momento, a autoridade indígena Guambiana retomou as ações de controle ao cultivo da papoula. Algumas informações indicam que as reações da liderança Guambiana constituíam uma estratégia para fugir das funestas consequências causadas pela fumigação.

Os indígenas se comprometeram a acabar com a flor maldita, base da heroína, e o governo eliminou essa região de seu plano de fumigações com glifosato. O governo também se comprometeu a aumentar sua presença nessa região. Não se trata somente de obras de tratamento de esgoto, energia, água potável, estradas, mas, também projetos agrícolas necessários para substituir rapidamente os cultivos de papoula (REVISTA SEMANA, COLÔMBIA, 20/07/1992). 
A capacidade de negociação alcançada pelo Movimento Guambiano, durante o processo de recuperação de terras, foi uma vez mais colocada em teste no cenário de mediação política com as entidades governamentais. A erradicação manual foi executada e conseguiu-se acabar com o total do plantio ilícito existente, sob a exigência de que esse município seria excluído do plano de fumigações aéreas e da outorga de investimentos para a promoção do desenvolvimento territorial.

Em troca pela erradicação total dos cultivos ilícitos no município, estava implícita a exigência de mudanças substanciais na política de luta contra as drogas ilícitas. A demanda dos guambianos era a construção de uma política social integral para esse território. Nela deveriam incluir-se ações de controle ambiental, proteção da identidade étnico-cultural, fortalecimento da organização e autonomia comunitária e, em geral, as velhas demandas para o processo de recuperação territorial. Segundo os depoimentos, a resposta do governo foi tardia e limitada a investimentos isolados para a produção agrícola.

\section{O caso da Reserva Indígena de Pitayó}

Durante décadas, os habitantes desta reserva ficaram presos a uma dinâmica de dependência clientelista para atenção dos problemas locais. Isso explicaria a desconfiança com as instituições locais de representação dos interesses coletivos. Na interiorização da vida social, há uma predisposição mediante a qual a liderança indígena é percebida como alheia aos interesses comunitários.

Porém, nem sempre foi assim. Os indígenas Paez, do mesmo modo que outros povos nativos na América, caracterizavam-se pelo destaque do interesse comum. A individualidade como princípio do agir em sociedade é um legado do período colonial. Conforme afirma Pino (2002), a divisão social fomentada pelos partidos políticos tradicionais foi um obstáculo para a reconstrução da identidade sob o passado que abriga a tradição milenária. O habitus, como disposição adquirida, cimentou aqui modos de ser e fazer (BOURDIEU, 2007). Embora estes indígenas pertençam a uma comunidade étnica historicamente reconhecida, neles predominam práticas individualistas que dificultam a coesão do grupo social. O impacto da violência simbólica e a interiorização da cultura dominante foram maiores neste espaço territorial. Experiências passadas, guardadas na memória do coletivo social, indicam constrangimentos diante do agir dos grupos de poder, porém, aos poucos, certo consentimento ou resignação apoderou-se desse grupo. Assim, o desinteresse pelas situações ligadas a dinâmica coletiva instalou-se como um padrão de comportamento socialmente aceitável.

No que diz respeito ao tratamento da expansão do cultivo da papoula, somente na década de 1990, diante das ações promovidas pelo governo central em resposta às negociações lideradas pelos Guambianos, os habitantes da reserva 
começaram um processo de erradicação manual desse plantio. A carência de iniciativas próprias de controle permitiu à papoula expandir-se nesse território e permanecer ainda hoje.

Estes agricultores familiares erradicaram a papoula, sob a condição de receber investimentos públicos. Voltaram ao plantio ilícito quando não receberem tais investimentos com a presteza estabelecida no acordo. Adiante, serão discutidas as limitações do enfoque da política pública com a qual se tenta mitigar este fenômeno. Porém, antecipando a discussão, afirma-se que uma das dificuldades que se enfrenta diz respeito à disponibilidade de grandes investimentos. Dado que estes crescem em menor ritmo do que o dos cultivos ilícitos, a outorga dos recursos para os projetos produtivos nunca será suficiente para as famílias vinculadas ao plantio ilícito. Assim, o impacto dessa estratégia limita-se à execução de projetos isolados. Nessa situação, os agricultores que não conseguiram ser atingidos pelos incentivos governamentais permanecem no plantio ilícito, como mecanismo de garantir sua subsistência.

Durante esta pesquisa de campo, foram observados plantios de papoula em Pitayó. Pequenas porções de terra nas quais a cebola, a batata, a abóbora e a papoula crescem em aparente harmonia. Ironicamente, no campo municipal, esta localidade abriga o maior número de agricultores familiares beneficiários dos projetos governamentais, no âmbito da cooperação com os Estados Unidos: "Plano Colômbia", com os quais se pretende substituir papoula por outros cultivos.

\section{A experiência da Reserva Indígena de Kizgó}

Não há produção acadêmica sobre esta reserva e, por esse motivo, a discussão nesta parte, sustenta-se nas declarações obtidas na pesquisa de campo. Segundo os relatos dos informantes, a configuração da reserva remonta a 1886. Tem uma extensão territorial de aproximadamente cinco mil hectares e uma população estimada em seis mil habitantes. "O povo Kizweñotem como principal característica a interculturalidade. É uma comunidade indígena com características particulares resultado da mistura entre os povos Paez e Guambiano ${ }^{16 "}$.

Esta reserva é o único espaço territorial do município de Silvia que ainda hoje permanece livre do cultivo de papoula. Nela, a autoridade indígena liderou um esforço mediante o qual conseguiu controlar a expansão desse cultivo no seu território. Esse processo começou na década de 1980. Apesar de não contar com uma estratégia claramente definida, aos poucos, consolidaram mecanismos para manter a reserva livre do plantio ilícito.

16 http://silvia-cauca.gov.co/nuestromunicipio, acesso em 20 de março de 2008. 
Estávamos muito preocupados porque cada vez eram mais cultivos e mais indígenas envolvidos. Então, mediante as "mingas" 17 se erradicaram os cultivos. Começou a aparecer gente armada que ameaçava a autoridade indígena. Um dia chegamos a um cultivo e tinham segurança armada. Eram guerrilheiros das Farc, da Frente Jacobo Arenas, que estavam protegendo esses cultivos. Foi uma situação complexa: teve ameaças e muita briga. Sem se deixar intimidar pelos conflitos internos a erradicação continuava. (AFP2. Entrevista realizada em 18/12/2007).

Até aqui podem ser identificadas duas diferenças entre o reagir desta reserva e os dois casos estudados antes: a força da liderança kizweña na regulação do conflito e a coerência no tocante à importância do processo de construção territorial. É sobre a ameaça de ser expulso da reserva, e as implicações disso derivadas, que é erguida a estratégia de controle a expansão da papoula. Uma desvantagem deste grupo populacional diante dos Guambianos e os Pitagueños é que sua aparição como organização social - fruto da mistura entre as etnias mais representativas - é relativamente nova no território. Portanto, o desafio da organização consiste em consolidar-se como um grupo étnico reconhecido.

Somos uma mistura, com costumes e identidade diferentes. Não somos Paez, pois, não falamos a língua deles. Nem somos guambianos autênticos porque nem falamos, nem usamos as vestimentas tradicionais deles. Temos nossas próprias características, somos indígenas Kizweños (AFP2. Entrevista realizada em 18/12/ 2007).

Em consequência, a procura do reconhecimento como grupo étnico constitui um dos pilares sobre os quais se arquiteta esse coletivo social. Disso decorre que a liderança assumiu o desafio de manter-se livre da papoula em sua reserva, sob ameaça de expulsão do indígena que incorporasse essa lavoura. Tal expulsão implicava um castigo que limitava o indígena, não somente da exploração da terra senão, fundamentalmente, de pertencer a esse grupo social.

A estratégia de erradicar forçosamente o cultivo da papoula nesta reserva pode ser considerada uma experiência de sucesso, uma vez que conseguiram manter sem papoula seu território até hoje. Mas, essa ação implicou em novas manifestações de conflito. Por isso, os incentivos promovidos pelo governo central na década de 1990, foram procurados pelas lideranças da reserva na tentativa de oferecer novas alternativas para sua comunidade.

17 Palavra que provém do quéchua minka, com a qual as comunidades andinas denominavam o trabalho agrícola coletivo em benefício da comunidade indígena em geral. Na Colômbia, a palavra minga é usada para referir trabalhos comunitários entre parceiros, não é remunerado, e procura a ajuda mútua dos envolvidos. Semelhante ao "mutirão" no Brasil. 
Os projetos e os investimentos da estratégia do governo central focam-se nos produtores atuais de cultivos ilícitos. Ironicamente, no caso de Kizgó, a estratégia de manter livre de papoula sua reserva converteu-se em obstáculo para acessar aos incentivos da política pública. Diante dessa situação, a leitura que essa comunidade faz é que seu esforço foi castigado, e que os agricultores familiares envolvidos com o plantio ilícito são premiados pelo governo. Essas contradições na execução dessa política foram discutidas por Thoumi et al. (1997). Os autores afirmam que as estratégias promovidas por essa política criaram incentivos errôneos no agricultor familiar, plantar ilícitos é o mecanismo para que o governo realize investimentos na sua propriedade.

$\mathrm{O}$ enfoque proibitivo dessa política somente reconhece como resultado válido a diminuição dos hectares plantados com cultivos ilícitos. Por isso não inclui mecanismos de prevenção que permitam abordar o atendimento dos problemas que levam aos agricultores familiares a plantar culturas ilícitas. Nesse sentido, a afirmação de Thoumi et al. (1997) é coerente: focar os incentivos dessa política exclusivamente no agricultor familiar que planta papoula, embora não necessariamente conduza à tornarem cultivadores de papoula, peca por deixar, por marginalizar da agenda pública de investimentos os agricultores familiares que, com suas próprias forças, enfrentam os problemas que os afetam.

\section{A política de luta contra as drogas ilícitas}

Trata-se de uma política focada no controle militar para mitigar o problema do narcotráfico. Porém, a análise aqui desenvolvida privilegia e destaca as estratégias que produzem maior impacto nos agricultores familiares. Esta política pública é executada desde 1984, e está ancorada em uma mistura de "garrote e cenoura" (LÓPEZ, 1997). Nesta metáfora, o "garrote" representa as ações repressivas como a fumigação aérea, e a "cenoura" refere-se à promessa de investimentos públicos para o "desenvolvimento alternativo" nas regiões que erradicam o plantio ilícito.

Uma análise dessa política à luz das cinco características consideradas na abordagem proposta por Stein et al. (2006) - estabilidade, consideração do interesse público, coerência, adaptabilidade, eficiência - permite mergulhar nas suas debilidades. Na execução das suas estratégias, essa política tem demonstrado incapacidade de introduzir mudanças em resposta ao comportamento da situação problema que se pretende atingir. Assim, parece que se trata somente de manter a estabilidade dessa política no tempo, quando o desafio radica na sua capacidade de incorporar as mudanças que permitam aproximar-se dos fins perseguidos.

A não consideração do interesse público leva a afirmar que esta política é estranha à problemática que tenta mudar (VARGAS, 1999). Nas regiões afetadas com a expansão dos cultivos ilícitos há velhos problemas agrários que ainda não foram 
resolvidos e que a política desvaloriza. As manifestações de inconformidade dos atores envolvidos são diversas: desde as "greves" dos agricultores familiares até a construção de uma proposta regional - Plano Alterno - que visava superar os limites dessa política. Porém essas iniciativas não têm sido bem sucedidas. Pelo contrário, o alinhamento da política colombiana com o enfoque promovido pelos Estados Unidos é cada vez mais notório. A inércia para responder adequadamente aos choques, que têm gerado o enfoque e as estratégias, reflete na fraca adaptabilidade às condições diversas que estimulam o plantio ilícito no país.

Os embates entre a estratégia de fumigaçãoe a estratégia de "desenvolvimento alternativo", deixaram a descoberto as falhas na coerência entre as estratégias adotadas pela citada política. A fumigação, longe de atingir o problema, gerou maiores complicações, pois, na tentativa de fugir desses efeitos, os cultivos ilícitos avançam em novas regiões de difícil acessibilidade e vulnerabilidade social, econômica e ambiental (VARGAS, 1999).

O desenvolvimento alternativo proposto limita-se ao impulso de projetos agrícolas. Nos casos onde esses projetos foram desenvolvidos, os impactos produzidos foram contrários aos esperados. A baixa aptidão para a exploração agrícola incidiu na baixa "competitividade no curto prazo dos projetos substitutivos diante da rentabilidade das lavouras ilícitas, com o agravante que se consolidou a vigência da economia ilegal como a única, segura e real fonte de renda para essas regióes" (VARGAS, 1999, p. 127). Falhas na execução dessa estratégia influenciaram o insucesso na alocação desses investimentos: não se tinha garantida de comercialização para os novos produtos. Em segundo lugar, os créditos oferecidos foram outorgados em porcentagens mínimas: dos cinco mil créditos solicitados em 1996, somente conseguiram outorgar 127. Aliás, alguns cultivos alternativos plantados foram atingidos pela fumigação aérea, evidenciando a ausência de algum tipo de coordenação entre as estratégias de combate à expansão do plantio ilícito.

De outro lado, a falta de coordenação é aprofundada pela fraqueza e dispersão dos organismos estatais que têm surgido como plataformas institucionais de suporte à política. A Direção Nacional de Entorpecentes (DNE) e o Conselho Nacional de Entorpecentes (CNE), responsáveis pela formulação e execução da política em questão, são fracas institucionalmente. $\mathrm{O}$ fato de não possuírem orçamento próprio limita a autonomia e a mobilidade dessas instâncias (LÓPEZ, 1997).

A ausência de retornos sociais concretos sobre a diminuição do plantio ilícito coloca em xeque a eficiência na alocação de investimentos públicos. Como já dito, as mudanças esperadas não acontecem porque a política não atinge as causas centrais que levam os agricultores familiares a plantar cultivos ilícitos. Mesmo assim, uma alta porcentagem dos recursos é destinada à fumigação aérea, sendo que os projetos para a substituição recebem uma mínima quantia. No período 
1992-1998, 53,2 milhões de dólares foram investidos na fumigação ${ }^{18}$ de 19.472 hectares de papoula e 46.400 de coca, diante de sete milhões de dólares para beneficiar a aproximadamente 30.000 agricultores familiares (COLÔMBIA, 1994a).

A permanência dos agricultores familiares no plantio ilícito junto ao crescimento dos hectares plantados contesta a eficiência dessas estratégias. No mais recente informe do Sistema Integrado de Monitoramento de Cultivos Ilícitos $\left(\right.$ Simci $\left.^{19}\right)$, de 2007, reportava um crescimento de $27 \%$ dos hectares plantados. No caso do Departamento de Cauca, afirmou-se que tinha 280 hectares plantados com papoula, quantidade equivalente a $39 \%$ do plantio nacional (COLÔMBIA, 2007b).

\section{Conclusões}

O estudo de caso no município de Silvia permitiu confirmar de que há discordância entre a política pública de luta contra os cultivos ilícitos e os comportamentos sociais que visa mudar, o que explica o fracasso verificado. A complexidade histórica e socioeconômica do município de Silvia, como território receptor da expansão do cultivo da papoula, é a demonstração empírica da suspeita sobre a qual se embasou a presente pesquisa: essa política pública parte de uma concepção errada do problema, criminaliza os agricultores familiares e desvaloriza os conflitos existentes nesse território. O "diagnóstico errôneo" do problema não permitiu identificar instrumentos adequados para superálo. Partir de pressupostos equivocados na identificação do fenômeno levou a desenhar e executar estratégias que não atingem as causas geradoras dessa problemática.

A consideração feita sobre porque são mantidas as ações dessa política, embora seu fracasso esteja demonstrado, inspirou-se na abordagem sobre a violência simbólica (BOURDIEU, 1989). O enfoque dessa política nos países da América Latina obedece ao padrão imposto pelos Estados Unidos. No caso colombiano, a permanência nessa política comporta pelo menos duas

18 Em matéria de erradicação forçosa de cultivos ilícitos durante a administração Uribe, está sendo executada uma nova estratégia: os grupos móveis de erradicação manual - GME -, formados por agricultores familiares e ex-integrantes de grupos armados à margem da lei. Os GME sob a proteção das forças militares se deslocam para as regiões produtoras de cultivos ilícitos para erradicar esses plantios. Esta estratégia surge como resposta à redução dos investimentos do "Plano Colômbia". Fumigar um hectare de cultivos ilícitos custa 700 dólares, enquanto erradicá-lo manualmente tem um custo de 325 dólares (Revista Semana, Colômbia, 17/ 08/2007).

19 Parceria entre as Nações Unidas e o governo da Colômbia. Os dados sobre papoula são fornecidos pela Direção Antinarcóticos da Polícia Nacional - DIRAN. 
condicionantes: i) Estados Unidos é o principal sócio comercial da Colômbia e ii) alto grau de dependência dos investimentos da cooperação norteamericana. Essa relação é marcada pela "certificação" de "bom desempenho" na luta contra as drogas ilícitas. Uma "não certificação" ou avaliação negativa implica em sanções comerciais para Colômbia, fato que já aconteceu durante a administração Samper, no ano de 1994.

Procurou-se demonstrar que a inserção de agricultores familiares no plantio da papoula, embora esteja impulsionada pela expectativa de incrementar a renda familiar, corresponde também a outras motivações: em primeiro lugar, a limitação de acesso à terra, na papoula, sua exploração é rentável, ainda, num quarto de hectare. Em segundo lugar, a opção de "crédito fácil", para compra de sementes e insumos para a exploração da papoula, deve ser considerada face ao "vazio" existente no sistema de crédito para os agricultores familiares colombianos. Em terceiro lugar, essa cultura ilícita é de ciclo curto. Aliás, a matéria-prima obtida pelo agricultor familiar não é perecível, situação que facilita o estoque na espera de melhores preços para comercializar. Então, a inserção desses agricultores familiares nessa lavoura está associada às condições de existência e às maneiras de desejar e sentir o que é necessário. Deve-se, pois, contestar os pressupostos moralistas ou preconceituosos que afirmam possuírem esses agricultores familiares uma "tendência à ilegalidade".

A pesquisa também ressalta quatro fatores que mantiveram fora do plantio ilícito alguns agentes. Em primeiro lugar, esses agricultores familiares destacaram a importância que reveste o desfrute do reconhecimento social nos diferentes espaços da vida local e a participação no processo de tomada de decisões: aqueles agentes que desfrutam um espaço na estrutura de representação local não se arriscaram em se inserir no plantio ilícito. Em segundo lugar, o acesso à terra, que indica a pertinência da discussão sobre a reforma agrária, mas numa perspectiva "inovadora" que considere as condições do presente, na qual as instituições locais podem e devem jogar uma atitude proativa. $\mathrm{Ou}$ seja, não adianta exigir que os latifundiários abram mão da terra concentrada, se as lideranças indígenas, em razão da ausência de uma política de terra nas suas reservas, continuam a repetir o padrão concentrador. Em terceiro lugar, a posse de uma unidade familiar pluriativa como mecanismo de inserção econômica e social. Este comportamento implica, sobretudo, numa reafirmação da centralidade da categoria trabalho no capitalismo contemporâneo, sem desconsiderar os efeitos da sua precarização. Em quarto lugar, foi destacado o acesso à educação, cuja importância é reconhecida no processo de reconstrução da identidade e na identificação de novos espaços para ter a vida que esses agentes desejam.

Estes elementos destacados explicam a diferenciação nas formas de relação e reação diante dos conflitos sociais e, em particular, no tocante ao cultivo da papoula. Mas também, a reação de cada grupo social esteve marcada, 
de um lado, pelo legado histórico e, de outro, pela conjuntura política territorial. Assim, a heterogeneidade nas manifestações da dinâmica social, produzida pela interação com o mundo, é governada por regras específicas do território, e desafiada pelo enfoque atual colombiano para a promoção do desenvolvimento.

Os conflitos do município de Silvia reclamam pela mudança institucional no território. Não se trata simplesmente de problemas associados ao crescimento econômico: esse território abriga conflitos que dizem respeito à inconformidade dos seus agentes com a vida que têm. Neste contexto, as manifestações dos agricultores familiares indicam a necessidade de um "novo" enfoque de políticas públicas que os valorize socialmente.

\section{Referências Bibliográficas}

BOURDIEU, Pierre. O poder simbólico. Lisboa: Difel/Rio de Janeiro: Editora Bertrand Brasil, 1989.

. A distinção: crítica social do julgamento. Porto Alegre: Editora Zouk, 2007.

COLÔMBIA. Plan nacional compromiso de Colombia frente al problema mundial de la droga. Bogotá: Presidencia de la República, 1994a, 34 p.

2001a, $20 \mathrm{p}$.

. Plan Alterno. Gobernación del Cauca. Popayán: Gobernación del Cauca, . Auditoria especial a la política de erradicación de cultivos ilícitos. Bogotá: Contraloría General de la República CGR, 2001b, 70 p.

. Zonificación de los conflictos de uso de las tierras en Colombia. Bogotá: IGAC-CORPOICA, 2002, 120 p.

. Colombia: Monitoreo de Cultivos de coca. Bogotá: DNE 2007c, 30 p.

ESTRADA, J. El plan Colombia y la intensificación de la guerra. Aspectos globales y locales. Bogotá: Universidad Nacional de Colombia, Departamento de Ciencias Políticas, Observatorio Político, 2002.

FAJARDO, Darío. El Cauca indígena y el desarrollo rural. In: MACHADO, Absalón. Problemas agrarios colombianos. Bogotá: Siglo XXI. 1986.

FALS BORDA, Orlando. Historia de la cuestión agrícola en Colombia. $3^{\mathbf{a}}$ edição, Bogotá: Carlos Valencia, 1975.

JARAMILLO, Jaime. Historia, sociedad y cultura. Bogotá: UNIANDES, 2002

KALMANOVITZ, Salomón. Economía y nación. Bogotá: Tercer Mundo, 1994. 
LONDOÑO, Luis. El Consejo Regional Indígena Del Cauca -CRIC- Historia De Una Organización Indígena en su Lucha por La Tierra, El Territorio y Una "Economía Propia". Popayán: Departamento de Estudios Interculturales. Universidad Del Cauca, 2005.

LOPEZ, Andrés. Costos del combate a la producción, comercialización y consumo de drogas y a la violencia generada por el narcotráfico. In: THOUMI, et al. Drogas ilícitas en Colombia. Su impacto económico, político y social. Bogotá: PNUD, 1997.

MACHADO, Absalón. Problemas agrarios colombianos. Bogotá: Siglo XXI, 1986.

Las políticas y el modelo de desarrollo agropecuario. In: La academia y el sector rural 5. Bogotá: Universidade Nacional de Colômbia, 2005.

MARTINS, José de Souza. Em pauta, o direito de ser diferente. Publicado em O Estado de São Paulo [Caderno Aliás, A Semana Revista]. 31 de agosto de 2008, p. J4.

MUELAS \& URDANETA. La fuerza de la gente: juntando recuerdos sobre la terrajeria en Guambia-Colombia. Bogotá: Imprenta nacional de Colombia, 2005.

PERAFAN, Carlos. Impacto de cultivos ilícitos en pueblos indígenas. El caso de Colombia. Washington: PUND, 1999.

PINO, Guillermo. Las antinomias del poder local. Silvia en el Cauca indígena. Popayán: Universidad del Cauca, 2002.

REVISTA SEMANA. Si se puede: los indígenas del Cauca están demostrando que hay más de una manera de acabar con la amapola. 20 de julho de 1992.

ROCHA, C. La Economía colombiana tras 25 años de narcotráfico. Bogotá: UNDCP, Ministerio de Salud, 1995.

SCHNEIDER, Sergio. A pluriatividade e o desenvolvimento rural Brasileiro. Cadernos do Centro de Estudos Avançados e Multidisciplinares, Núcleo de Estudos Agrários, Brasília V.5, n.17, 2005, p.23 a 42.

SIABATO, Tarsicio. Perspectiva de la economía campesina. In: MACHADO, Absalón. Problemas agrarios colombianos. Bogotá: Siglo XXI, 1986.

STEIN, et. al. A política das políticas públicas. Progresso econômico e social na América Latina. São Paulo: Campus, 2006.

THOUMI, et al. Drogas ilícitas en Colombia. Su impacto económico, político y social. PNUD. Bogotá: Ariel, 1997.

VARGAS, Ricardo. Drogas, Poder y Región en Colombia: Impactos Locales y Conflictos. Bogotá: CINEP, 1995.

. Fumigación y conflicto. Políticas antidrogas y deslegitimación del Estado en

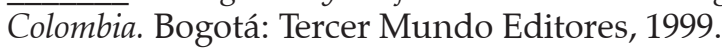

